\title{
Proposta de um índice de Sustentabilidade para subsidiar políticas públicas de desenvolvimento sustentável no município de Tremembé em relação à extração de areia por cavas
}

\author{
Mariuza Figueiredo Lindenberg ${ }^{1}$ \\ Marcelo dos Santos Targa ${ }^{2}$ \\ Hélio Nóbile Diniz ${ }^{2}$ \\ Nelson Wellausen Dias ${ }^{2}$ \\ Benedito Jorge dos Reis ${ }^{3}$
}

\author{
${ }^{1}$ Universidade de Taubaté - UNITAU \\ Programa de Pós-Graduação em Ciências Ambientais \\ Estrada Mun. Dr. José Luiz Cembranelli, 5.000- 12080-010 - Taubaté - SP, Brasil \\ \{mariuzafl, targa.marcelo,nwdias\}@gmail.com; heliodiniz1@yahoo.com.br \\ ${ }^{2}$ E-COnsulting - Consultoria Ambiental \& Tecnologia da Informação Ltda. \\ contato@e-consultingltda.com.br
}

\begin{abstract}
The objective of this study is to propose a set of sustainability indicators specifically designed to evaluate sand mining activities in the Paraiba do Sul river valley in the State of São Paulo, Brazil. This study was conducted based on existing knowledge on hydrographic basin sustainability indicators and previous studies on the municipality of Tremembé, the main focus of this study. The result includes a set of indicators that together form the so-called ISCAVA (Sustainability Indicator of Sand Wholes) intended at establishing the level of sustainability of individual lakes left behind by the sand mining acitivity.
\end{abstract}

Palavras-chave: sustentabilidade, mineração de areia, vale do Paraíba, índices, monitoramento.

\section{INTRODUÇÃO}

$\mathrm{Na}$ formação de cidades ao longo da história os primeiros povoamentos humanos se estabeleceram próximos de rios e lagos para garantir o suprimento de água tanto para os seres humanos e animais, cultivos em solo fértil e transporte. Apesar de dependente da água para a manutenção da vida humana, presencia-se na atualidade a degradação da qualidade e redução da quantidade de água, principalmente pelo uso indiscriminado, por despejos de resíduos líquidos não tratados provenientes de cidades, indústria e plantações; remoção das matas ciliares e da vegetação ao redor de nascentes e da extração de areia. Como medida de controle dos usos da água no Estado de São Paulo, foi estabelecido em 1990 o Plano Estadual de Recursos Hídricos que culminou com a criação de 22 Unidades de Gerenciamento de Recursos Hídricos (UGRHIs). A Região de Tremembé, objeto deste estudo, pertence à UGRHI-02, Unidade de Gerenciamento de Recursos Hídricos da Bacia do Rio Paraíba do Sul, com $14.547 \mathrm{~km}^{2}$. De acordo com o relatório de situação dos Recursos Hídricos do Estado de (São Paulo, 2002), a bacia em questão apresenta como atividades predominantes a agropecuária e indústria destacando-se na primeira a pecuária leiteira e pastagem e na segunda a mineração. Esta extração é realizada na bacia principalmente nas margens dos rios levando à formação de lagos extensos e profundos que influenciam no balanço hídrico regional causando alterações climáticas (REIS, 2006). 
A extração de água além da capacidade de recarga natural dos aqüíferos em diversas regiões no globo terrestre tem provocado o rebaixamento do lençol freático. A planície ao norte da China, responsável por $25 \%$ da safra chinesa de grãos, sofre a cada ano o rebaixamento de 1,5 metros no seu lençol freático (YANG E ZEHNDER, 2001).

O lençol freático na região do Vale do Paraíba está, provavelmente, sendo rebaixado. A bacia de drenagem do rio Paraíba do Sul encontra-se na região com maior densidade populacional do Brasil, ou seja, o eixo São Paulo - Rio de Janeiro, e já apresenta sérios problemas de disponibilidade hídrica (ANA, 2003). Esse rebaixamento deve estar ocorrendo em parte devido a retificação do Rio Paraíba do Sul, em parte pela extração de água excessiva e também pelo aumento de espelhos d’água formados de atividades como pesque e pague e extração de areia em cavas nas planícies aluviais que favorece a evaporação da água.

Segundo VALVERDE (2001), a extração de areia nas várzeas do rio Paraíba do Sul, para uso na construção civil, corresponde a $10 \%$ da produção nacional e é da ordem de $1.023 .836 \mathrm{~m}^{3}$ mensais (DNPM, 2005) e responde por cerca de $25 \%$ da produção areeira do Estado de São Paulo (REIS et al., 2005). A extração de areia no Vale do Paraíba teve seu início no final da década de 40 na cidade de Jacareí, o passar dos anos e o desenvolvimento da atividade foi crucial para o desequilíbrio ambiental na região, tanto da vegetação quanto dos lençóis freáticos localizados as margens do rio Paraíba do Sul, na região compreendida entre as cidades de Jacareí e Tremembé. Quando é feita a recuperação florestal das áreas ao entorno das cavas desativadas pós-mineração baseadas na Resolução SMA/42 pode haver a melhora da condição ambiental e a atração da fauna e flora locais podendo também melhorar a biodiversidade após o impacto ambiental causado pela atividade mineradora. Os estudos recentes indicam uma taxa de uso e ocupação do solo avançada na Bacia do Rio Paraíba do Sul devido ao desenvolvimento crescente nessas áreas como mineração, áreas alagáveis para cultivo do arroz, urbanização e industrias.

Sabe-se que o principal usuário de água nessa bacia hidrográfica, em termos de volume de captação, é o setor de irrigação com $49,73 \mathrm{~m}^{3} / \mathrm{s}$, seguido pelo abastecimento urbano que utiliza cerca de $16,5 \mathrm{~m}^{3} / \mathrm{s}$ e pelo setor industrial que capta cerca de $13,65 \mathrm{~m}^{3} / \mathrm{s}$ e, finalmente, o setor de pecuária com consumo inferior a $4 \mathrm{~m}^{3} / \mathrm{s}$ (SÃO PAULO, 2002).

A bacia sedimentar de Taubaté contém grande quantidade de cascalhos e seixos intercalados em leitos de argilas e areias em disposição entrecruzada (SÃO PAULO, 1999). Devido a essa formação geológica nos arremete a pensar como uma bacia de retenção, armazenamento e liberação de água de infiltração, capaz de manter a perenidade do rio todo o ano. O fluxo de base pode chegar à totalidade da vazão do rio durante certas épocas do ano.

Pelas condições de relevo regional, a classificação climática de Koeppen, do município de Taubaté Cwa, ou seja, clima úmido com temperaturas quentes no verão e com inverno ameno, será aplicada a Tremembé. A temperatura média do mês mais frio é inferior a $18^{\circ} \mathrm{C}$, apresentando um período de seca no inverno, sendo a temperatura média nos meses de verão superiores a $22^{\circ} \mathrm{C}$ e a precipitação do mês de julho é aproximadamente $10 \%$ da precipitação do mês de janeiro (FISCH, 1995).

Percebe-se uma tendência cada vez maior de determinação de índices mesuráveis para auxiliar as análises de processos e serviços relacionados com a administração pública. Existem vários indicadores para cada ramo ou segmento que se queira analisar: indicadores de desempenho, para avaliar pessoas e projetos; indicadores econômicos financeiros, para a comparação de empresas e países; indicadores sócio-econômicos e para análise da sociedade entre outros, resumindo uma série de informações que auxiliam a tomada de decisão pelo administrador (BOSSEL, 1999).

Um desses índices é o índice ISBH proposto por ISAIAS, (2008) que estabelece uma metodologia de análise da sustentabilidade de recursos hídricos para subsidiar políticas 
públicas. Neste trabalho busca-se a proposição de um índice de sustentabilidade, a nível municipal, com o intuito de subsidiar os gestores da administração pública local no desenvolvimento e na adoção de políticas públicas voltadas para a sustentabilidade. O índice proposto será baseado no ISBH de ISAIAS, 2008 tendo também as variáveis ambiental, de qualidade da água, socioeconômico e político institucionais. Difere do ISBH por propor um índice de esfera municipal e por utilizar outras variáveis e indicadores adaptados à realidade da bacia local. Uma das variáveis a ser estudada é a CAVA como referência ao impacto decorrente da extração de areia para o município e região.

Essa atividade mineradora se apresenta de forma intensiva no Vale do Paraíba e pode comprometer o uso futuro das águas e das terras agricultáveis que cedem crescente espaço para as cavas. Ao analisar imagens de satélite da região do vale do Paraíba, Reis et. al., (2005) observaram um crescimento da área das cavas de 192\% no período de 1993 a 2003, enquanto a evaporação da lâmina d'água formada pela extração de areia em cava apresentou um crescimento na evaporação de $203 \%$, no mesmo período. A figura 1 apresenta as cavas de areia existentes em 2003 no trecho compreendido entre Jacareí e Pindamonhangaba.

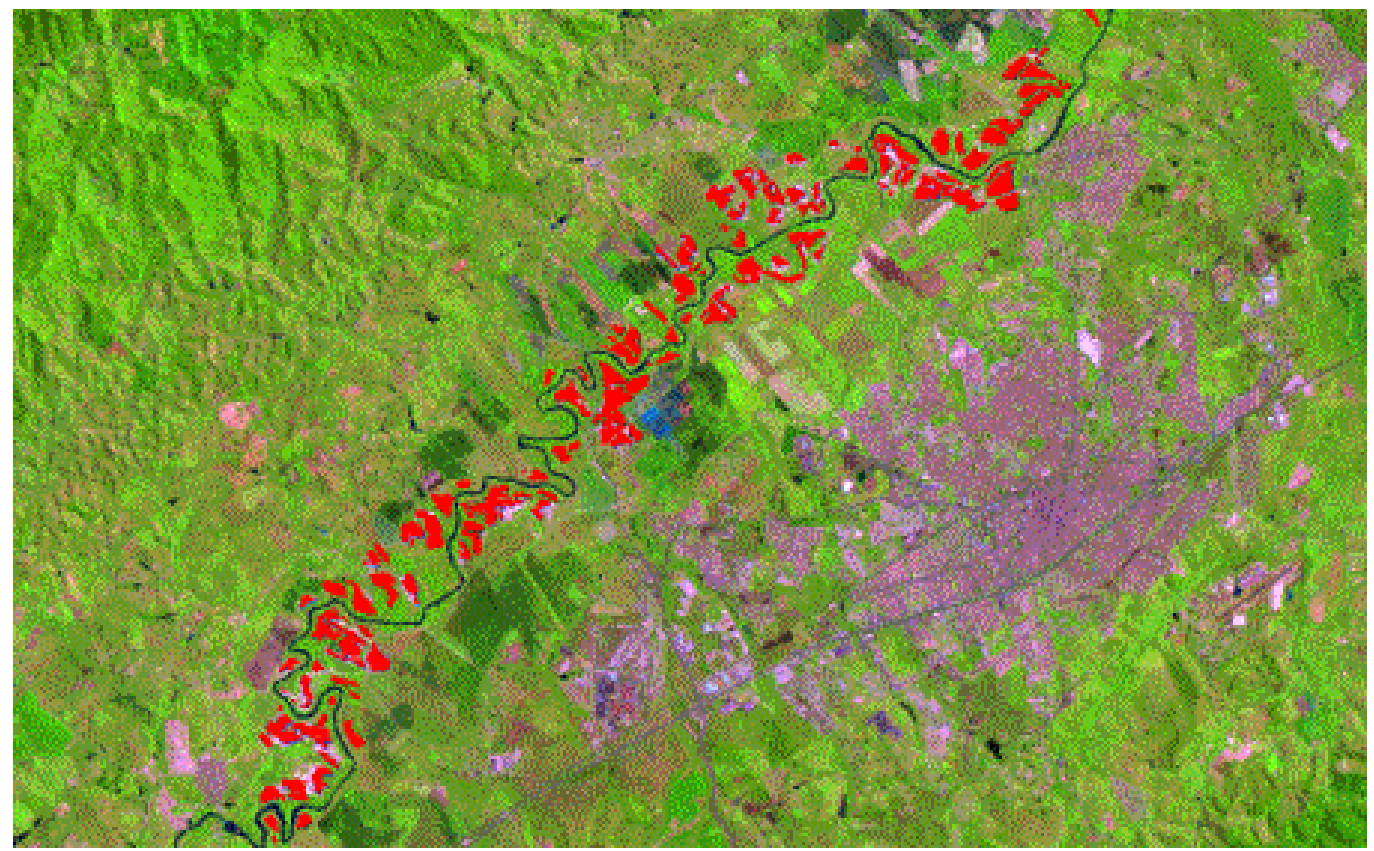

Figura 2. Cavas de areia ano 2003 (em Vermelho)

Fonte: Reis, B.J. et. al., 2005

Em geral as cavas de areia consomem anualmente, por evaporação, aproximadamente 2,8 vezes mais água do que o cultivo do arroz irrigado por unidade de área (REIS, 2006). Portanto, como demonstra a Tabela 1, a água perdida por evaporação das cavas de areia seria suficiente para o plantio de 4.789 ha de arroz irrigado no Vale do Paraíba levando a reflexão sobre o censo conservador de que a agricultura irrigada é a maior consumidora de água conforme afirma CHRISTOFIDIS (1999), o que é reforçado por TARGA et. al., (2002) que demonstra o balanço hídrico positivo para o cultivo de arroz inundado em várzea . 
Tabela 1. Estimativa das Perdas de Água para a Atmosfera por Evaporação em Áreas de Lagos das Cavas de Extração de Areia.

\begin{tabular}{rccccccr}
\hline ANO & $\begin{array}{c}\text { ÁREA } \\
\text { LAGOS (ha) }\end{array}$ & $\begin{array}{c}\text { PREC. } \\
\text { ANUAL } \\
(\mathrm{mm} / \mathrm{ano})\end{array}$ & $\begin{array}{c}\text { PREC. NA ÁRA } \\
\text { DE LAGOS } \\
\left(\mathrm{m}^{3} / \mathrm{ano}\right)\end{array}$ & $\begin{array}{c}\text { ECA } \\
(\mathrm{mm} / \mathrm{ano})\end{array}$ & $\begin{array}{c}\text { EL }=\mathrm{Kp} \\
\text { (mm/ano) }\end{array}$ & EL (m $\left.{ }^{3} / \mathrm{ano}\right)$ & $\begin{array}{c}\% \\
\text { EL/PREC. }\end{array}$ \\
\hline 1993 & 591 & 1.432 & 8.468 .132 & 1.405 & 1.068 & 6.313 .536 & 75 \\
1994 & 699 & 1.220 & 8.532 .490 & 1.452 & 1.103 & 7.714 .356 & 90 \\
1995 & 807 & 1.493 & 12.048 .016 & 1.317 & 1.001 & 8.078 .175 & 67 \\
1996 & 915 & 1.608 & 14.713 .110 & 1.320 & 1.003 & 9.177 .958 & 62 \\
1997 & 1.023 & 1.086 & 11.103 .517 & 1.403 & 1.066 & 10.906 .689 & 98 \\
1998 & 1.126 & 1.253 & 14.099 .818 & 1.341 & 1.019 & 11.473 .031 & 81 \\
1999 & 1.229 & 1.316 & 16.174 .186 & 1.420 & 1.079 & 13.256 .984 & 82 \\
2000 & 1.332 & 1.552 & 20.670 .458 & 1.353 & 1.028 & 13.692 .597 & 66 \\
2001 & 1.435 & 1.146 & 16.444 .086 & 1.523 & 1.158 & 16.608 .828 & 101 \\
2002 & 1.537 & 1.365 & 20.991 .078 & 1.511 & 1.149 & 17.659 .196 & 84 \\
2003 & 1.726 & 1.033 & 17.841 .444 & 1.460 & 1.110 & 19.157 .022 & 107 \\
\hline \multicolumn{2}{c}{ TOTAIS } & 14.505 & 161.086 .335 & 15.505 & 11.784 & 134.038 .372 & 83 \\
\hline
\end{tabular}

Fonte: Reis et. al., 2005

\section{OBJETIVO}

O presente trabalho tem por objetivo apresentar uma proposta para o estabelecimento de um índice de sustentabilidade para subsidiar políticas públicas do município de Tremembé com relação aos possíveis usos para as cavas de areia desativadas.

\section{METODOLOGIA}

Tremembé é uma Estância Turística, localizada no estado de São Paulo na latitude $22^{\circ}$ 57' 45 e longitude $45^{\circ} 33^{\prime} 17$ a $544 \mathrm{~m}$ do nível do mar. De acordo com o senso do IBGE (2006) tem um território com $192,42 \mathrm{~km}^{2}$ e uma população de 38.231 pessoas. Sua topografia apresenta morro e várzeas. O clima é quente com inverno seco e sua economia é voltada para a agropecuária, rizicultura, pequenas empresas e serviços. De acordo com a Prefeitura local cerca de $86 \%$ de seu território encontra-se na zona rural e abriga cerca de 4000 pessoas.

A proposição dos indicadores de sustentabilidade apresentados neste artigo são oriundos de análise documental focada nas condições específicas da área de várzea do município de Tremembé e da futura disponibilidade de dados que serão gerados a partir de pesquisa em andamento na área de interesse. Nesta pesquisa serão obtidos dados meteorológicos direcionados para os estudos hidrológicos utilizando Estação Meteorológica Automática A740 capaz de medir os parâmetros para determinação do balanço hídrico (Chuva, temperatura, Umidade Relativa e Evaporação). Também será feita a medição do nível do lençol freático automaticamente por meio de equipamento eletrônico que será instalado em piezômetros. A medição será feita durante doze meses em intervalos de 15 minutos. Será feita a medição de parâmetros físico-químicos de qualidade da água diretamente nos corpos d'água e no interior dos piezômetros por meio de equipamentos automatizados de medição de parâmetros múltiplos de qualidade da água (medidores multiparâmetro). Os equipamentos serão capazes de medir, no mínimo, os seguintes parâmetros limnológicos: temperatura, turbidez, oxigênio dissolvido, $\mathrm{pH}$, condutividade elétrica, taxa de oxi-redução e total de 
sólidos dissolvidos. A medição desses parâmetros ocorrerá quinzenalmente em todos os piezômetros e nas cavas durante doze meses. Também será realizado o mapeamento do uso e cobertura da terra do município de Tremembé e em especial, com foco nas áreas de cava, será utilizado aquele realizado pela empresa REGEA - Geologia e Estudos Ambientais proveniente de imagem de alta resolução do Satélite Ikonos II de 29 de abril de 2006, e que é parte integrante da Carta Geotécnica do Município de Tremembé e serviu de base para a elaboração do Plano Diretor, os quais serão integrados em um banco de dados por meio do software SPRING, Sistema de Processamento de Informações Georreferenciadas (CÂMARA, et. al. 1996).

\section{RESULTADOS}

Com base na análise das informações existentes e na perspectiva de dados a serem obtidos pelo projeto em andamento, foram propostos os indicadores que, juntos, constituem o Índice de Sustentabilidade das Cavas ou ISCAVA, conforme descrito abaixo.

\section{Construção do Índice de Sustentabilidade das Cavas}

O índice proposto, baseado no ISRH (ISAIAS, 2008), levanta também variáveis e indicadores para as dimensões envolvidas. Com a ponderação dos mesmos será proposta uma fórmula. O valor encontrado, adimensional, representará o indicador ISCAVA (Índice de Sustentabilidade das Cavas).

A organização hierárquica dos componentes do ISCAVA seguirá a orientação proposta no ISBH (ISAIAS, 2008), indicado na Tabela 2.

Tabela 2. Organização hierárquica dos componentes do índice ISCAVA

\begin{tabular}{|l|l|}
\hline Componentes & CARACTERÍSTICAS \\
\hline Índice & Representa a integração equitativa das dimensões do ISCAVA \\
\hline Dimensão & $\begin{array}{l}\text { As dimensões que compõem o ISTRE são representadas pela equação dos } \\
\text { indicadores }\end{array}$ \\
\hline Indicador & Representam os fatores que compõem as dimensões \\
\hline Variável básica & Constitui a base de dados que compõe os \\
\hline
\end{tabular}

Os dados levantados que compõe o ISCAVA serão estruturados em planos de informação PI's que serão associados e georreferenciados em ambiente SIG originando um banco de informações temáticas e cadastrais. As diversas dimensões abrangidas pelos indicadores individuais apresentados na Tabela 3 (ambiental, qualidade de água, evaporação, lençol freático, político institucional e consumo de água) permitem avaliar a sustentabilidade pelos seus principais pilares, mas devidamente adaptados ao tema a que se propõem avaliar, no caso a sustentabilidade das cavas de areia.

\section{CONSIDERAÇÕES FINAIS}

A aplicação do ISCAVA para o município de Tremembé deverá permitir visualizar com mais clareza os impactos causados pela extração de areia e a consequente formação de lagos (cavas). E, dessa forma, servir de instrumento de informação para auxiliar o poder público municipal na tomada de decisões e no estabelecimento de metas na direção do desenvolvimento sustentável para o município. 
Tabela 3. Dimensão, indicadores e variáveis básicas para o desenvolvimento do índice ISCAVA.

\begin{tabular}{|c|c|c|}
\hline Índice & Dimensões & Indicadores e variáveis básicas \\
\hline \multirow[t]{7}{*}{$\begin{array}{l}\text { Índice de } \\
\text { Sustentabilidade } \\
\text { de Cava de } \\
\text { Areia } \\
\text { ISCAVA }\end{array}$} & $\begin{array}{l}\text { Dimensão } \\
\text { Ambiental } \\
\text { (DAM) }\end{array}$ & $\begin{array}{l}\text { IC= Cobertura Vegetal } \\
\text { IRE= Índice de recebimento de efluentes } \\
\text { IR=Índice de recebimento diverso } \\
\text { IRAMB= Indicador responsabilidade Ambiental da Mineradora } \\
\text { IACAVA/Arroz=área de cavas x área de cultivo de arroz }\end{array}$ \\
\hline & $\begin{array}{l}\text { Dimensão } \\
\text { Qualidade da água } \\
\text { (DQA) }\end{array}$ & $\begin{array}{l}\text { IQA= Índice de qualidade da água } \\
\text { ITurbidez= Índice de Turbidez } \\
\text { IEutrof=Índice de Eutrofização }\end{array}$ \\
\hline & $\begin{array}{l}\text { Dimensão } \\
\text { Evaporação (DEV) }\end{array}$ & $\begin{array}{l}\text { IEVAPO=Índice Evaporação da cava } \\
\text { IAPP=Indicador de Integridade de Área de Preservação } \\
\text { Permanente } \\
\text { IVEV/AR=volume evaporado das cavas x volume de água } \\
\text { consumida na rizicultura }\end{array}$ \\
\hline & $\begin{array}{l}\text { Dimensão Lençol } \\
\text { Freático (DLF) }\end{array}$ & IRLF= Indicador de rebaixamento de nível de lençol freático \\
\hline & $\begin{array}{l}\text { Dimensão Político } \\
\text { Institucional (DPI) }\end{array}$ & $\begin{array}{l}\text { ICAV= Indicador referente à \% de Atividades de mineração } \\
\text { legal em relação a atividades de Extração Irregulares } \\
\text { IEAMB= Indicador de Educação Ambiental }\end{array}$ \\
\hline & $\begin{array}{l}\text { Dimensão Social } \\
\text { Econômica (DSE) }\end{array}$ & $\begin{array}{l}\text { R=Indicador de contribuição de Renda para o Município } \\
\text { IEMPRE=Indicador de empregos fornecidos pelas mineradoras } \\
\text { IRS=Indicador Responsabilidade Social da Mineradora } \\
\text { IV=volume de areia extraído x arrecadação de } \\
\text { CFEM. }\end{array}$ \\
\hline & $\begin{array}{l}\text { Dimensão Consumo } \\
\text { de Água (DCA) }\end{array}$ & $\begin{array}{l}\text { ICM= Indicador do montante de consumo de água do } \\
\text { município com projeção para } 10 \text { anos } \\
\text { ICB= Indicador do montante de consumo da bacia com } \\
\text { projeção para } 10 \text { anos }\end{array}$ \\
\hline
\end{tabular}

\section{REFERÊNCIAS BIBLIOGRÁFICAS}

ANA. Agência Nacional de Águas, 2003. Documento eletrônico www.ana.gov.br/pnrh obtido em 29 de maio de 2005.

BOSSEL, H. Indicators for Sustainable Development: Theory, Method,. Applications. A Report to the Balaton Group. ...www.igeo.pt/instituto/cegig/got/17_Planning/.../bossel_1999. pdf .

CAMARA, G.; SOUZA, R. C. M.; FREITAS, U. M. et al. SPRING: Integrating remote sensing and GIS by object-oriented data modelling. Computers \& Graphics, v. 20, n. 3, p. 395403, 1996.

CHRISTOFIDIS, D. Recursos hídricos e irrigação no Brasil. In: Workshop Disponibilidade de Água e Irrigação no Nordeste, 1999, Brasília. Texto... Brasília: ISPN, 1999. 34p.

DNPM - DEPARTAMENTO NACIONAL DA PRODUÇÃO MINERAL. Anuário mineral brasileiro. Brasília: Departamento Nacional da Produção Mineral, 2005. v. 34, 426p.

FISCH, G. Caracterização climática e balanço hídrico de Taubaté (SP). Revista Biociências, 1995. 1(1):81-90. 
INSTITUTO NACIONAL DE METEOROLOGIA - INMET: disponível em http: www.inmet.gov.br, acesso em junho, julho, agosto e setembro de 2009.

IBGE. População e Domicílios - Censo 2000; Censo Agropecuário 2006. Disponível em: http://www.ibge.gov.br/cidadesat/default2.php. consultado em outubro de 2009.

ISAIAS, F. B. A Sustentabilidade da água: Proposta de um índice de sustentabilidade de bacias hidrográficas. 2008. 168 f. Dissertação (Mestrado) - Departamento de Centro de Desenvolvimento Sustentável, Universidade de Brasília, Brasília, 2008. Disponível em: $<\cdot$ http://repositorio.bce.unb.br/handle/10482/1153?mode=full\&submit_simple=Mostrar + item + e $\mathrm{m}+$ formato+completo $>$. Acesso em: 10 set. 2009.

MARQUES, E. D. ; SILVA FILHO, E. V. ; TUBBS, D. ; SANTElli, R. E. ; SElla, S. M. . Alumínio dissolvido nas águas das cavas de extração de areia: um estudo das possíveis implicações de sua toxicidade, Município de Seropédica, RJ. In: Workshop de Geologia Médica, 2005, Rio de Janeiro. Anais do Workshop de Geologia Médica, 2005. v. Único.

REIS, B. J. Avaliação da expansão da atividade de extração de areia na planície aluvial da bacia hidrográfica do Rio Paraíba do Sul no trecho entre Jacareí e Pindamonhangaba no período de 1993 a 2003. Dissertação de Mestrado em Ciências Ambientais. Universidade de Taubaté. 112 p. 2005.

REIS, B. J.; BATISTA, G. T.; TARGA, M. S.; CATELANI, C. S. Influência das cavas de extração de areia no balanço hídrico do vale do Paraíba do Sul. Rem: Rev. Esc. Minas, Dez 2006, vol.59, no.4, p.391-396.

SÃO PAULO (Estado). Secretaria de Recursos Hídricos Saneamento e Obras. Documento Estratégico de Negociação - Projeto de Qualidade das Águas e Controle da Poluição na bacia do rio Paraíba do Sul, 1999.

SÃO PAULO. Plano de Recursos Hídricos - Relatório de Situação dos Recursos Hídricos do Estado de São Paulo. Secretaria de Recursos Hídricos, Saneamento e Obras. Departamento de Águas e Energia Elétrica. São Paulo, Departamento de Águas e Energia Elétrica, 2002. 199p. : Il.

SIMI, R.; SIMI JUNIOR, R; RUDORFF, B.F.T. Monitoramento e Análise da Evolução das Cavas de Areia na Várzea do Rio Paraíba do Sul. Anais XIV Simpósio Brasileiro de Sensoriamento Remoto, Natal, Brasil, 25-30 abril 2009, INPE, p. 5467-5474.

TARGA, M.S.; BATISTA, G.T.; PEREIRA, J.B.P.A.; REIS, B.J. Reflexões e Considerações sobre a Cobrança do Uso da Água para o setor Agropecuário da Bacia do Rio Paraíba do Sul - Câmara Técnica de Cobrança de Uso da Água - CBH-PS. Universidade de Taubaté. Taubaté, SP. 2002. p: 1-13. disponivel em www.agro.unitau.br/lageo.

YANG, H., ZEHNDER, A. J. B. China's regional water scarcity and implications for grain supply and trade. Environment and Planning 33, 79-95. 2001. 